\title{
STRATEGI PEMBELAJARAN TAHFIDZ DAN TAJWID DALAM \\ MENINGKATKAN SKILL MENGAJAR AL-QUR'AN \\ (STUDI KASUS DI PGMI UNISDA)
}

\author{
Akhmad Yusron \\ Prodi Pendidikan Guru Madrasah Ibtidaiyah - Fakultas Agama Islam \\ Universitas Islam Darul 'Ulum Lamongan \\ J1. Airlangga No. 03 Sukodadi Lamongan \\ Email: yusron@unisda.ac.id
}

\begin{abstract}
The needs of the Islamic community towards the learning of the Qur'an are increasing. Madrasah Ibtidaiyah is one of the Islamic education institutions that accommodate these needs through the memorization program Juz 'Amma and Tajweed science learning.

PGMI UNISDA as one of the study programs that prints MI teacher candidates, presents a Tahfidz and Tajweed Learning course. Hafalan Juzz 'Amma is part of the Tahfidz program that is in line with the needs of the current basic education institution. Tajwid science is also taught to improve the recitation of the Qur'an and the creation of Tartil and fluent readings. The learning strategy of Tahfidz and Tajwid subjects at PGMI UNISDA is based on the Tajwari Jazariyyah book that has been compiled by the lecturer. This translated book from the Matan Jazariyyah book is considered to have the material needed to be able to read the Qur'an fluently. Discussion about Makharij Al-Letter, Nature of Letters, Tarqiq and Tafkhim are basic needs to be able to read the Qur'an fluently.

The learning system used in the learning of Tahfidz and Tajwid is to link the memorization thoroughly with the presence presence. PGMI students at each meeting are required to deposit a number of letters that have been determined. Students can complete letters Juz 'Amma in 12 meetings. Juz 'Amma memorization is a condition that a student can take the final semester examination in the form of Munaqasah Juz' Amma.
\end{abstract}

Keywords: Al-Qur'an Learning, Tajweed 


\begin{abstract}
Abstrak
Kebutuhan masyarakat Islam terhadap pembelajaran Al-Qur'an semakin meningkat. Madrasah Ibtidaiyah adalah salah satu dari lembaga pendidikan Islam yang mengakomodir kebutuhan tersebut melalui kegiatan program menghafal Juz 'Amma dan pembelajaran ilmu Tajwid.

PGMI UNISDA sebagai salah satu program studi yang mencetak caloncalon guru MI, menghadirkan suatu matakuliah Pembelajaran Tahfidz dan Tajwid. Hafalan Juzz 'Amma merupakan bagian dari program Tahfidz yang sesuai dengan kebutuhan lembaga pendidikan dasar saat ini. Ilmu Tajwid juga diajarkan untuk memperbaiki bacaan Al-Qur'an dan terciptanya bacaan Tartil dan fasih. Strategi pembelajaran matakuliah Tahfidz dan Tajwid di PGMI UNISDA berpedoman pada buku Tajwid Jazariyyah yang telah disusun oleh dosen pengampu. Buku terjemah dari kitab Matan Jazariyyah ini dinilai memiliki materi yang dibutuhkan untuk dapat membaca Al-Qur'an secara fasih. Pembahasan seputar Makharij al-Huruf, Sifat Huruf, Tarqiq dan Tafkhim merupakan kebutuhan pokok untuk dapat membaca Al-Qur'an secara fasih.

Sistem pembelajaran yang digunakan dalam pembelajaran Tahfidz dan Tajwid adalah mengaitkan tuntas hafalan dengan presensi kehadiran. Mahasiswa PGMI di setiap pertemuan wajib menyetorkan beberapa surat yang telah ditentukan. Mahasiswa dapat mentuntaskan surat-surat Juz 'Amma dalam 12 kali pertemuan. Tuntas hafalan Juz 'Amma menjadi syarat seorang mahasiswa dapat mengikuti ujian akhir semester dalam bentuk Munaqasah Juz 'Amma.
\end{abstract}

Kata Kunci: Pembelajaran Al-Qur'an, Ilmu Tajwid

\title{
A. Pendahuluan
}

Dewasa ini banyak dijumpai lembaga-lembaga madrasah Ibtidaiyah baik di daerah pedesaan maupun kota telah menerapkan program menghafal Juzz 'Amma bagi anak didiknya. Hafalan Juzz 'Amma menjadi penciri dari sebuah lembaga pendidikan dasar Islam yang ingin mempertegas kata "Qur'ani” dari visi suatu MI. Setiap pagi awal masuk MI, anak-anak disambut dengan bacaan tilawah yang diperdengarkan melalui speaker madrasah. Selain bertujuan untuk mengkondisikan lingkungan madrasah dengan suasana yang religius, juga menjadikan anak terbiasa mendengar lantunan bacaan Al-Qur'an dan memberikan keberkahan dalam diri anak. ${ }^{1}$ Hal ini menjadi salah satu faktor yang menarik para orang tua untuk menyekolahkan anaknya di MI yang menerapkan program tersebut.

\footnotetext{
${ }^{1}$ Wawancara dengan Ibu Hj. Isti'anah Nikmah, selaku Kepala MI Darul Ulum 2 Kudus, pada tanggal 12 Februari 2016.
} 
Masyarakat luas juga mulai sadar pentingnya pembelajaran Al-Qur'an. Terlebih pada bulan Ramadhan, mereka tersugesti dengan tayangan-tayangan di Televisi yang menyiarkan kompetisi anak-anak dalam bertilawah dan Tahfidz, seperti; Hafidz Indonesia yang ditayangkan oleh RCTI dan Semesta Bertilawah yang disiarkan di MNC TV. Banyak orang tua muslim sekarang mulai berbangga ketika anak-anak mereka bisa menghafal Al-Qur'an. Testimoni dari beberapa pejabat Kepolisian menyatakan bahwa ingin anak-anak mereka alim Al-Qur'an. Sebagaimana pernyataan Kapolres Tuban, Bapak AKBP Sutrisno dalam sambutannya di forum komunikasi pondok pesantren (FKPP) Tuban menyatakan bahwa beliau bangga kalau anaknya bisa menjadi orang yang alim agama dan mampu menghafalkan Al-Qur'an. ${ }^{2}$ Sama halnya yang juga disampaikan Bapak AKBP Moh. Irhamni, selaku Wakil direktur di Polda Metro Jaya yang menyatakan dirinya kelak akan menitipkan anaknya di lembaga pesantren agar bisa hafal Al-Qur'an.

Berdasar kebutuhan masyarakat inilah, program studi PGMI membekali calon lulusannya dengan kompetensi hafalan Juzz 'Amma dan pemahaman ilmu Tajwid yang menjadi skill penunjang yang dibutuhkan oleh lembaga MI favorit di wilayah Lamongan dan sekitarnya.

\section{B. Pembahasan}

Program studi PGMI Universitas Islam Darul 'Ulum Lamongan memiliki visi menjadi pusat studi keislaman yang terkemuka, berdaya saing kuat, mandiri dan bertaraf internasional pada tahun 2031. Ditunjang dengan misi prodi yakni melaksanakan pendidikan tinggi yang berkualitas yang menghasilkan lulusan yang profesional, mempunyai keunggulan kompetitif di bidang studi keislaman.

Untuk menjadi pusat studi keislaman yang terkemuka yang mampu menghasilkan lulusan yang memiliki keunggulan dalam wilayah kajian Islam, maka prodi ini menekankan muatan pembelajaran Al-Qur'an dari segi ilmu Tajwid dan wawasan Qur'aninya. Pembelajaran Tajwid menjadi urgen sebagai salah satu kompetensi utama dalam ranah keterampilan di bidang rumpun mata pelajaran PAI. Untuk menjadikan lulusan yang berdaya saing, prodi PGMI UNISDA juga membekali kemampuan teoritik dalam ilmu Tajwid yang diintegrasikan dengan kemampuan hafalan Juz 'Amma.

Di daerah Lamongan, hafalan Juz 'Amma merupakan pembelajaran yang umum dijumpai. Banyak dari MI menjadikannya sebagai program wajib dari madrasah. Hal ini menjadi amanah bagi calon pendidik MI untuk membekali dirinya minimal memiliki hafalan Juz 'Amma. Sebagai calon pendidik MI, praktek hafalan Al-Qur'an juga harus dibarengi dengan kompetensi pengetahuan yang

\footnotetext{
${ }^{2}$ Dokumentasi pada tanggal di Gedung Asrama Haji Tuban.
} 
dibutuhkan dalam memahami hukum bacaan Al-Qur'an. Alasan inilah yang mendasari mata kuliah ini menggabungkan kompetensi Tahfidz dan ilmu Tajwid.

Sebagai orang Islam, selain kewajiban yang mendasari untuk mempelajari ilmu Tajwid juga banyak keutamaan-keutamaan yang dijelaskan dalam Hadis, seperti;

خيركم من تعلم القر اءن و علمه

Artinya: "Sebaik-baik kalian adalah orang yang belajar Al-Qur'an dan mengajarkannya."

Dan juga didasari oleh hadis lain yang berbunyi:

$$
\text { لا ظل الا ظله مع انبيائه واصفيائه حصال نبل نبيكم وحب اهل بيته وقر اءة القران فان حملة القران فى ظل الله يوم }
$$

Artinya: "Didiklah anakmu dengan tiga perkara, yaitu mencintai Nabimu,

mencintai keluarga Nabi, dan membaca Al-Qur'an, sesungguhnya orangorang yang menghafal Al-Qur'an berada pada perlindungan Allah swt pada hari tidak ada perlindungan kecuali lindungan-Nya bersama-sama dengan Nabi-nabi dan Sahabat-sahabatnya yang tulus" (H.R. AdDailami $^{3}$

Ilmu Tajwid merupakan salah satu bagian dari Ulum al-Qur'an. Minimal seorang Muslim menguasai ilmu Tajwid karena berkaitan dengan ibadah lain seperti Salat. Karena ibadah seperti Salat memiliki rukun yang bersifat Qauli dan juga merupakan bagian dari Al-Qur'an. Tujuan baca tulis Al-Qur'an adalah mempersiapkan anak didik untuk dapat menjadi generasi Muslim yang Qurani, yaitu generasi yang mencintai Al-Qur'an, menjadikan Al-Qur'an sebagai bacaan, dan sekaligus pandangan hidup sehari-hari. Tidak dibenarkan bagi orang yang tidak bisa membaca Al-Qur'an dengan baik dan fasih untuk mengajarkan Al-Qur'an. Belajar Al-Qur'an merupakan suatu kewajiban dan tanggung jawab. Oleh karena itu, umat Islam harus mempelajari dan mengamalkan ajaran-ajaran yang terkandung di dalamnya. Kebutuhan ini dapat terpenuhi manakala seseorang mau belajar ilmu Tajwid dan menggurukan bacaannya.

Belajar Al-Qur'an berarti harus belajar sesuatu yang terkait dengannya yaitu, makharij al-huruf dan sifat-sifat huruf untuk memperindah pengucapan dengan sefasih-fasihnya bahasa. ${ }^{4}$ Pernyataan tersebut sesuai dengan ayat AlQur'an yang berbunyi:

\footnotetext{
${ }^{3}$ Lihat kitab Mukhtar al-Hadits an-Nabawiyyah karangan Sayyid Ahmad Hasyimi, hadits ke48.

${ }^{4}$ Syamsuddin Muhammad bin Muhammad al-Jazari, Matan Jazariyyah (Surabaya: Saad bin Nashir bin Nabhan, tt), hlm.4
} 
Artinya: "Atau lebih dari seperdua itu. dan bacalah Al Quran itu dengan perlahan-lahan/bertajwid". 5

Lulusan PGMI harus membekali dirinya dengan kompetensi dalam ilmu Tajwid Al-Qur'an untuk dapat mengajarkan anak-anak MI belajar membaca AlQur'an dengan baik. ${ }^{6}$ Ilmu Tajwid menjadi bekal utama agar seseorang dapat membaca Al-Qur'an dengan Tartil. Sebab yang dimaksud dengan tartil, sebenarnya adalah membaca Al-Qur'an sesuai dengan kaidah-kaidah ilmu Tajwid, menyempurnakan artikulasi huruf dan tentu saja beserta memperhatikan makna ketika waqaf (berhenti) maupun ibtida' (mulai). ${ }^{7}$ Tidak cukup dengan itu saja tetapi harus musyafahah (bimbingan yang diberikan seorang guru dalam melafalkan bacaan dan murid menirukannya dalam tatap muka secara langsung) dengan seorang guru yang sudah mendapat ijazah (izin mengajarkan Al-Qur'an) dan dianggap sudah cukup untuk dapat memberikan teladan seperti perilaku yang diajarkan Rasulullah Saw. ketika menerima wahyu. ${ }^{8}$

Peraturan pemerintah yang mendasari dimunculkannya mata kuliah Tahfidz dan Tajwid yang berorientasi pada peningkatan kemampuan dalam membaca AlQur'an adalah Surat Keputusan Bersama (SKB) Menteri Dalam Negeri dan Menteri Agama RI No. 128 / 44A, yang secara eksplisit ditegaskan bahwa umat Islam agar selalu berupaya meningkat kemampuan baca tulis Al-Qur'an dalam rangka peningkatan dan penghayatan dan pengamalan Al-Qur'an dalam kehidupan sehari-hari. Ditegaskan pula dalam Instruksi Menteri Agama RI No. 3 Tahun 1990 yang menyatakan "Agar umat Islam selalu berupaya meningkatkan kemampuan baca tulis Al-Qur'an".

Pola pengajaran menggunakan referensi baku dari buku yang berjudul Tajwid Jazariyyah. Buku ini disusun oleh dosen pengampu matakuliah Pembelajaran Tahfidz dan Tajwid dan merupakan terjemah dari kitab Matan alJazariyyah. ${ }^{9}$ Kitab Matan Jazariyyah ditulis oleh Syaikh Ibn al-Jazari. Nama lengkap beliau adalah Abu al-Khair Syamsuddin Muhammadd bin Muhammad bin Muhammad bin Ali bin Yusuf al-Jazari as-Syafi 'i. ${ }^{10}$ Beliau lebih dikenal dengan Syaikh Syamsuddin atau hanya disebut Ibn al-Jazari. Alasan kitab ini

\footnotetext{
hlm. 846

${ }^{5}$ Q.S. Al-Muzzammil ayat 4, Al-Qur'an dan Terjemahannya, Depag RI, Jakarta, 2002,

${ }^{6}$ Wawancara dengan Kaprodi PGMI UNISDA, Bapak H. Agus Anas, Lc.M.Pd.I pada tanggal 12 April 2018.

${ }^{7}$ Ibid.

${ }^{8}$ Lajnah Muroqobah Yanbu'a Cabang Mojokerto, Sekilas Ulumul Qur'an dan Fawatissuwar, LMY Cabang Mojokerto, 2012, hlm.8

9 Wawancara dengan Akhmad Yusron, M.Pd.I, selaku dosen pengampu mata kuliah Pembelajaran Tahfidz dan Tajwid pada tanggal 13 April 2018.

${ }^{10}$ Syamsuddin Muhammad bin Muhammad al-Jazari, Matan Jazariyyah, Saad bin Nashir bin Nabhan, Surabaya, tt, hlm.1
} 
dialihbahasakan oleh penulis untuk dijadikan referensi utama dalam pembelajaran Tahfidz dan Tajwid, dikarenakan pembahasannya lebih lengkap dibanding dengan kitab-kitab ilmu Tajwid yang umumnya dipelajari, seperti; kitab Hidayah alMustafid, Fath ar-Rahman fi Tajwid al-Qur'an, Hidayah as-Shibyan fi Tajwid alQur'an, Risalah al-Qurra' wa al-Huffazh, dan Tuhfah al-Athfal.

Kitab Matan al-Jazariyyah terdiri dari tiga pokok pembahasan meliputi: Makharij al-huruf, Sifat-sifat huruf, dan Tafkhim dan tarqiq. Ketiga pokok pembahasan inilah yang ditekankan dalam pembahasan buku terjemahan yang dijadikan pedoman oleh mahasiswa dalam belajar Al-Qur'an. Seperti pada umumnya buku ilmu Tajwid, buku tersebut juga memuat pembahasan seperti; pembahasan huruf Lam, Idgham Mutamảtsilain wa Mutajảnisain, hukum Nun sảkinah wa tanwin, macam-macam Madd, pembahasan Waqaf wa Ibtidả', serta pembahasan Maqhtu' wa Maushul. ${ }^{11}$

Dosen menekankan pembahasan Makharij al-huruf, Sifat-sifat huruf, dan Tafkhim dan tarqiq dengan harapan dapat menjadikan mahasiswa PGMI menjadi guru yang memiliki kompetensi bacaan Al-Qur'an secara fasih. Meskipun demikian selain ketiga pokok pembahasan tersebut yang sebenarnya sudah sering diajarkan oleh lembaga pendidikan Al-Qur'an, namun dalam buku ini disajikan dengan pembahasan yang lebih mendalam.

Melalui pembahasan Makharij al-huruf, mahasiswa dibekali kemampuan untuk membedakan tempat keluarnya (makhraj) yang sama-sama berasal dari tenggorokan (al-Halaq). Seperti huruf $\&$ dan $\diamond$ yang harus dikeluarkan dari tenggorokan yang paling dalam, huruf $\varepsilon$ dan $\tau$ yang harus dikeluarkan dari tenggorokan bagian tengah, dan huruf $\dot{\tau}$ dan $\dot{\varepsilon}$ yang harus dikeluarkan dari $\dot{\tau}$ dan $\dot{\varepsilon}$ yang harus dikeluarkan dari tenggorokan yang terdekat dengan mulut. Dalam makhraj al-Lisan, mahasiswa dapat membedakan huruf 0 dan yang harus

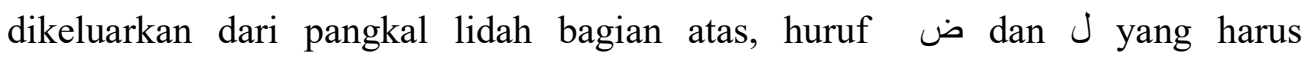

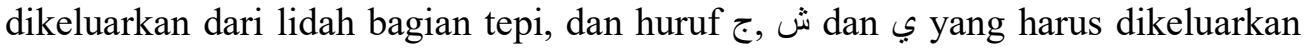
punggung lidah, dan huruf $\dot{ن}, \mathcal{J}, \dot{\Xi}$ dan yang harus dikeluarkan dari bagian

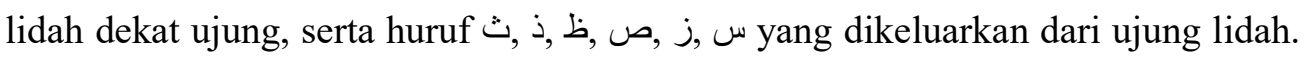
Perlu perhatian pula, ketika membaca Nun (ن) sảkinah ketika dibaca Idgham Mistlain, Ikhfa' Syafawi, semua tempat pada bacaan di atas mengeluarkan bunyi dari pangkal hidung.

Mahasiswa dalam pembelajaran Tahfidz dan Tajwid juga diajarkan kompetensi pengetahuan dan keterampilan terkait Sifat Huruf. Seperti pembacaan huruf $s$ dan $ت$ perlu diperhatikan dengan baik, tidaklah sama seperti mengucapkan huruf "k" dan "t". Mengingat kedua huruf tersebut bersifat Hams, yang dikenal dengan arti "mendesis". Maksudnya adalah mengeluarkan atau menghembuskan nafas ketika mengucapkan huruf karena lemahnya tekanan

\footnotetext{
${ }^{11}$ Ibid. hlm.1
} 
terhadap makhraj tersebut. Sifat Hams huruf 5 dan $\bullet$ harus ada penekanan dan tidak terlalu berlebihan dalam mendesis. Sehingga tidak dikhawatirkan huruf bisa terbaca menjadi bunyi "c" pada lafal آَكْبَ dan begitu pula huruf ت pada lafal يَتُُِْ bisa terbaca "yatlu".

Dalam pengucapan huruf yang bersifat Jahr (jelas) harus bersungguhsungguh, tidak diperbolehkan terbawa dialek orang Jawa yang seharusnya mengucapkan huruf بang di-waqaf menjadi "P" dan mengucapkan huruf ج yang di-waqaf menjadi “C”, seperti pada contoh; كحب الله, بالصبر, بربوة, اجتث, حج البيت " Ketika membunyikan huruf-huruf yang keluar dari makhraj Isti'la', posisi lidah terangkat ke langit-langit mulut bagian atas ketika mengucapkan huruf-huruf tersebut dan tidak semua bagian lidah naik tetapi hanya bagian pangkal lidahnya saja. Sebaliknya makhraj Istifal, posisi ujung lidah turun ke dasar mulut. Meskipun ketika diucapkan posisi lidah terlihat seperti naik ke atas. ${ }^{12}$

Lebih sulit pada pengucapan ص,ض, ط, ط yang merupakan huruf-huruf Ithbaq, dimana pangkal dan bagian tengah lidah naik ke atas sampai bagian lidah tengah tersebut bertemu dengan langit-langit bagian atas atau sampai sekiranya suara benar-benar dapat keluar secara terpusat di antara tempat itu. Pengucapan sifat Ithbảq berbeda dengan sifat Istifảl, dimana huruf Istifảl terlihat dari posisi pangkal lidah naik tetapi tidak sampai menyentuh langit-langit mulut bagian atas.

Dalam pengucapan huruf ص,j, صuga harus berhati-hati, karena ketiganya bersifat Shafir. Sifat Shafir artinya bunyi seruit suara burung berkicau/bersiul. Maksudnya adalah ketika mengucapkan huruf-huruf Shafir, terdengar suara tambahan yang keluar di antara gigi depan dan ujung lidah. Seperti ketika س membunyikan ص terdengar seperti suara angsa, j seperti suara lebah, dan seperti suara belalang. Terlebih pada pengucapan huruf-huruf yang tergabung dalam sifat Qalqalah, seperti dari sifat Jahr, namun dalam kenyataannya cara membacanya sedikit berbeda. Ketika dalam membunyikan sifat Jahr nafas tercegah, maka dapat dipantulkan suara dari tempat keluarnya huruf yang tersumbat itu secara seketika dan tidak terlalu lama. ${ }^{13}$

Pada pengucapan huruf ض bila tidak diucapkan dengan hati-hati, maka bisa salah dan samar-samar akan terdengar seperti huruf $b$. Mengingat kedua huruf ini sama dalam makhraj-nya namun bagian tempat mengeluarkannya berbeda. Huruf berasal dari bagian dekat ujung lidah, sementara huruf ض berasal dari tepi lidah. Dalam segi pengucapan, huruf ini tidak ada padanannya di huruf latin. Sehingga kebanyakan orang Indonesia tidak mampu mengucapkannya dengan tepat tanpa digurukan. Huruf ini mempunyai sifat yang khas, yakni; Istithảlah, tempat keluarnya huruf ini memanjang dari permulaan bagian tepi lidah sampai

\footnotetext{
${ }^{12}$ Akhmad Yusron, Tajwid Jazariyyah (Lamongan: Unisda Press, 2018), hlm.14.

${ }^{13}$ Ibid., hlm. 16.
} 
pusat tempat keluarnya huruf J. Jadi cara membunyikannya diambil dari bagian mulut yang dalam, selanjutnya diulur maju ke depan menuju keluar sampai tempat keluarnya huruf $\mathrm{J}$ seperti gerak lenturnya karet.

Kasus yang sama ditemui dalam pengucapan huruf $ش$, bila tidak diucapkan dengan hati-hati akan terjadi kesalahan dan bunyi yang keluar adalah bunyi huruf . Mengingat kedua huruf tersebut sama-sama berasal dari makhraj Lisan, namun untuk huruf ش penekanannya lebih kuat karena berasal dari bagian punggung lidah.

Mahasiswa juga dibekali dalam kemampuan membaca Tarqiq dan Tafkhim dalam kasus-kasus yang terinci, seperti;

a. Tidak boleh membaca tebal pada huruf dalam bacaan رحمة الله menjadi $b$, karena kebiasaan lisan orang Jawa lebih mudah mengucapkan huruf $ت$ dengan dibaca tebal ketika diharakati Dlammah. Ketika dibaca tipis saat Dlammah, maka sifat Hams (mendesis) dari huruf $ت$ akan cenderung mudah keluar.

b. Tidak sampai membaca tebal pada huruf ذ yang diharakati Fathah dalam bacaan ذللت supaya tidak menjadi ظ. Ketika ذ dibaca tebal akan terkesan bahwa ذ adalah huruf Ithbaq padahal bukan.

c. Tidak sampai ikut-ikutan membaca tebal huruf w ketika jatuh sebelum huruf $b$, فوسطن seperti pada lafal

Kompetensi yang ditargetkan, Mahasiswa PGMI dapat membedakan dimana huruf $J$ dan $J$ harus dibaca Tarqiq dan Tafkhim. Kewajiban membaca Tarqiq pada huruf $\lrcorner$, terjadi pada keadaan ketika $\lrcorner$ disukun dan jatuh setelah Kasrah, serta memenuhi syarat:

a. Huruf setelah $\lrcorner$ tidak berupa huruf Isti 'la' (huruf setelahnya adalah Istifal),

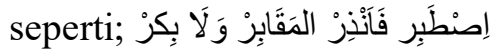

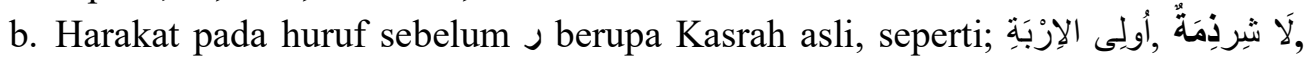
مَزيَةِ

Bacaan Tarqiq (ringan) juga terjadi pada huruf $\lrcorner$ yang disukun 'aridli

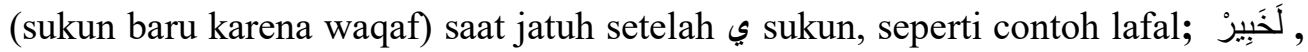

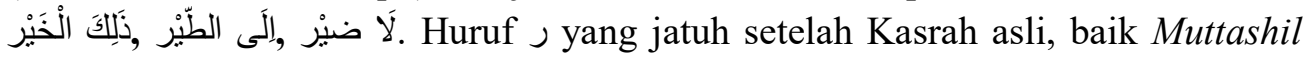
(satu kata) atau Munfashil (dalam kata yang berbeda), semua wajib dibaca Tarqiq (ringan), seperti; مِنْ الَبَنِ ارْتَتَنُُْ

Dengan merujuk kepada buku yang disusun dari sumber relevan, mahasiswa PGMI dapat terhindar dari kesalahan yang sering terjadi ketika kebanyakan orang membaca huruf tipis pada huruf yang tergabung dalam lafal خص ضغط فظ, Sejumlah huruf tersebut tetap dibaca Tafkhim dan harus tetap terpelihara tebalnya, meski saat di-kasrah. Perlu kehati-hatian jangan sampai membaca Tarqiq pada lafal seperti: طِبَاقا, ملقِيْكِ, ظِلالها . 
Selain pada kasus tersebut, bacaan Tafkhim terjadi ketika huruf $\lrcorner$ bertemu huruf Isti 'la' dan masih di dalam satu kalimat seperti contoh;

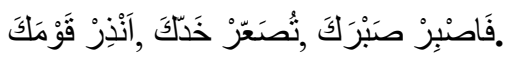

Begitu halnya dibaca Tafkhim, sebelum J terdapat harakat Kasrah yang tidak asli (aslinya Sukun namun karena di-washal maka diganti Kasrah untuk memperlihatkan bahwasanya huruf tersebut aslinya Kasrah), seperti; ارْتَضَىى, maupun harakat Kasrah tersebut tidak asli, bahkan 'Aridli dan Munfasil (dalam kata yang berbeda), seperti contoh;

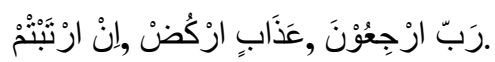

Pada kasus J sukun terletak pada harakat Fathah atau Dlammah, juga

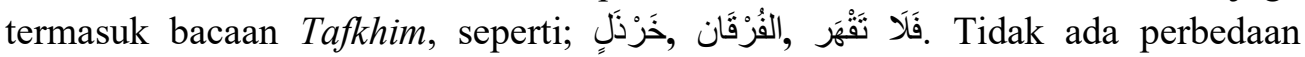
apakah J sukun 'Aridli (tidak asli) yang jatuh setelah Fathah atau Dlammah tersebut, keadaannya Muttashil (huruf berharakat Fathah atau Dlammah bertemu langsung dengan huruf $\lrcorner$ ) ataupun Munfashil (dipisah dengan huruf lain yang menimbulkan bacaan Madd), seperti;

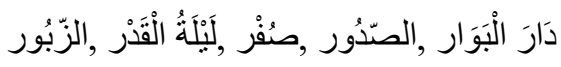

Adapun $\lrcorner$ yang dibaca Imalah, dibaca Tarqiq. Menurut qira'ah-nya Imam Ashim riwayat Hafsh, bacaan imalah tidak ada kecuali hanya satu pada lafal dimana $\lrcorner$ nya dibaca Tarqiq. Terjadi perbedaan di kalangan Ahl al-Ada' (guru ahli bacaan Al-Qur'an) mengenai huruf J nya فِرٍْ pada surat Asy-Syu'aro ayat 63. Ada yang membaca Tafkhim karena $J$ sukun menghadapi huruf ق (Isti'la') dan ada yang membaca Tarqiq karena hurufnya Isti'la' terbaca Kasrah, tebalnya sudah berkurang. Wajah dua ini bagus semua bisa pakai salah satunya. Juga bisa dua wajah, huruf $\lrcorner$ mati karena waqaf yang jatuh sesudah Kasrah yang terpisah dengan

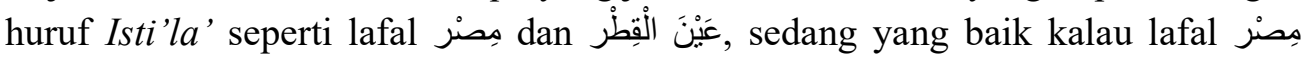
terbaca Tafkhim, dan عَيْنَ الْفِطُر terbaca Tarqiq. Karena melihat kalau diwashalkan

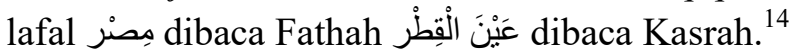

Sebaliknya dengan bacaan Taglizh (memberatkan) dengan membaca Tafkhim pada huruf lafal laat jatuh setelah huruf yang berharakat Fathah atau Dlammah, seperti lafal; نَصْرُ اللهِ وَواللهِ. Cara membaca ل seperti ini ditujukan untuk ta'zhim (mengagungkan Allah). Ketebalan huruf $J$ pada lafal الل J sulit digambarkan dalam bunyi lafalnya dalam huruf latin. Kata لله dalam bahasa Arab tidak bisa ditiru dalam bahasa latin dengan ditulis Alloh atau Awwoh.

Untuk itulah pengucapan tafkhim huruf $J$ pada lafal الله harus benar-benar diperhatikan. Cara mengucapkan tafkhim huruf $J$, semua lidah terutama pangkal lidah harus diangkat dan ditekan sampai merapat ke langit-langit mulut dengan menekan suara yang cukup kuat. Kalau tidak demikian, bunyi tafkhim $\mathrm{J}$ kurang

${ }^{14}$ Ibid., hlm.16. 
tepat. Penekan pangkal lidah dimaksudkan untuk mengucapkan huruf $\mathrm{J}$, sehingga bila penekanannya kurang tepat akan keluar bunyi “Awloh". Begitu pula ketika pangkah lidah tidak diangkat dan hanya menempelkan ujung lidah ke langit-langit mulut, suara yang keluar "Alloh" juga kurang tepat.

Untuk itulah pengucapan tafkhim huruf $J$ pada lafal الله harus benar-benar diperhatikan. Cara mengucapkan tafkhim huruf $\mathrm{J}$, semua lidah terutama pangkal lidah harus diangkat dan ditekan sampai merapat ke langit-langit mulut dengan menekan suara yang cukup kuat. Kalau tidak demikian, bunyi tafkhim J kurang tepat. Penekan pangkal lidah dimaksudkan untuk mengucapkan huruf $\mathrm{J}$, sehingga bila penekanannya kurang tepat akan keluar bunyi "Awloh". Begitu pula ketika pangkah lidah tidak diangkat dan hanya menempelkan ujung lidah ke langit-langit mulut, suara yang keluar "Alloh" juga kurang tepat. Bila sudah merasa bisa, tidak diperbolehkan terlalu cepat membaca tafkhim $\bigcup$ pada lafal Jalalah ini. Bila terlalu cepat akan mengakibatkan terlipat dan samar bunyinya. Disamping itu, bacaan الله wajib terdapat Maad (panjang), tidak boleh kurang dari 1 alif (2 harakat). Meskipun dalam tulisannya, huruf $J$ ditulis hanya menggunakan harakat Fathah.

Selain pembahasan yang jarang dibahas di buku ilmu Tajwid, pembahasan Idgham juga dibahas dalam pembelajaran Tahfidz \& Tajwid. Hal yang membedakan penjelasan Idgham di mata kuliah ini dengan materi Idgham di pembelajaran Tajwid lain adalah pada penekanan klasifikasi Idgham dari segi sempurna atau tidak mendengungnya. Bagi seseorang yang hanya butuh praktis mungkin sudah diajarkan materi Idgham secara singkat. Namun untuk menjadi pengajar adalah memasukkan huruf mati ke dalam huruf hidup yang berada setelahnya, dengan bacaan satu angkatan ber-tasydid (rangkap). Namun dalam kenyataannya, belum tentu huruf yang dibaca Idgham dapat menerima dijadikan Tasydid karena tedapat perbedaan sifat pada kedua huruf tersebut.

Untuk itulah dalam kaitannya cara pembacaan ini, dapat dibagi menjadi Idgham Naqish dan Idgham Tam. Pengertian Idgham Naqish adalah bacaan mendengung yang harus ditonjolkan karena tidak sempurnanya bacaan huruf awal ketika dimasukkan pada huruf kedua. Sementara Idgham Tam adalah peleburan dua huruf yang menjadi satu dengan pembacaan sifat makhraj yang satu. Termasuk dari kategori Idgham Naqish adalah beberapa contoh dari Idgham Mutajanisain. Sementara untuk kategori Idzgham Tam adalah Idgham Mutamatsilain, Idgham Mutaqaribain, Idgham Bila Ghunnah.

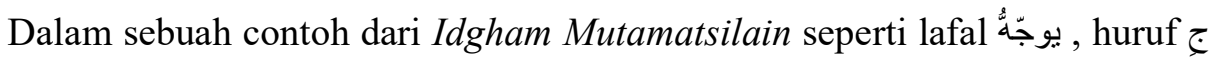
yang di-tasydid sebenarnya adalah dua huruf $ج$ yang sudah di-Idgham-kan. Karena kedua hurufnya sama persis, maka mudah dianggap sebagai bagian dari Idgham Tam (sempurna Idgham-nya tanpa harus menonjolkan sifat salah satu dari kedua huruf tersebut). Berbeda halnya dengan Idgham Mutajanisain yang merupakan Idgham Naqish yang pembacaan Idgham-nya tidak sempurna karena 
sifat huruf dari kedua huruf yang di-Idgham-kan berbeda, seperti pada huruf-huruf berikut;

a. Huruf $\doteq$ dan $\dot{j}$ adalah huruf yang keluar dari makhraj yang sama (makhraj alLisan) bahkan bagian lisannya sama yakni ujung lisan, namun kedua huruf ini mempunyai sifat yang berbeda. Seperti pada lafal Al-Qur'an, surat Al-A'raf

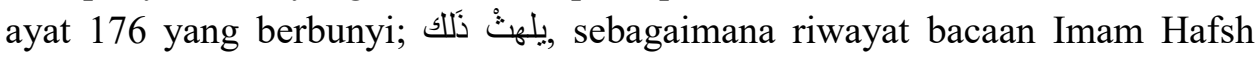
yang membaca يلكذ ذلك Sehingga dalam kasus ini dapat dianggap sebagai Idgham Tam.

b. Huruf $\varphi$ dan $>$ adalah huruf yang keluar dari makhraj yang sama, yakni makhraj al-Syafatain (dua bibir), namun kedua huruf ini mempunyai sifat yang berbeda. Huruf 4 mempunyai sifat Qalqalah (pantulan), sementara huruf $?$ tidak. Sehingga sifat Qalqalah ditiadakan dari huruf ب. Karena mempunyai makhraj yang sama, maka kedua huruf tersebut dibaca Idgham, seperti dalam lafal surat Hud ayat 42, yang berbunyi; اركب معنا.

c. Huruf b mati bertemu huruf $ت$, menurut kesepakatan ulama ahli Qiraat maka wajib dibaca Idgham Naqish (tidak sempurna idgham-nya). Huruf b (bersifat Tafkhim) harus dibaca jelas supaya tidak serupa dengan huruf $ت$ (bersifat Tarqiq). Caranya dengan mempertemukan lidah dengan langit-langit mulut. Tafkhim huruf b dipertahankan, sementara sifat Qalqalah huruf b tidak

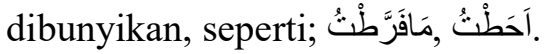

Selanjutnya Idgham Mutaqaribain, salah satu Idgham Naqish yang terjadi ketika dua huruf berdekatan makhraj dan sifatnya, yang awal mati dan huruf setelahnya hidup. Untuk lebih jelasnya, dapat dipaparkan contoh Idgham Mutaqaribain berikut ini.

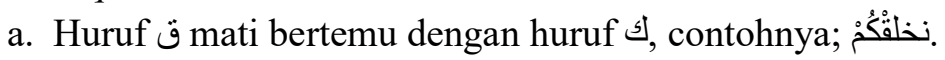

b. Menurut kesepakatan ulama ahli Qiraat, Huruf د mati bertemu huruf $ت$ maka wajib dibaca Idgham, Huruf د dan $ت$ adalah huruf yang keluar dari makhraj yang sama (makhraj al-Lisan) dan keduanya sama mempunyai sifat Syiddah (kuat), namun untuk huruf د punya sifat khusus, yakni Qalqalah. Untuk sifat

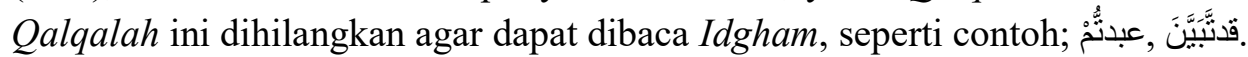

c. Menurut kesepakatan ulama ahli Qira'at, huruf wajib dibaca Idgham, seperti contoh;

وقالت طائفة , اجييت دعوتكما.

d. Huruf $\dot{j}$ dan balah huruf yang keluar dari makhraj yang sama dan bahkan keduanya pada makhraj al-Lisan, bagian lisan yang menjadi tempat keluarnya kedua huruf tersebut pun sama, yakni; ujung lidah. Keduanya juga mempunyai sifat yang sama, yakni sifat Rikhwah (kendor) dan Jahr (tidak berdesis). Seperti contoh; إذظظُّلموا

Melalui buku Tajwid Jazariyyah, mahasiswa juga diajarkan lafal-lafal yang seharusnya dibaca Izhhar. Biasanya pada pembahasan Izhhar di buku-buku Tajwid lain, lebih menekankan hukum Izhhar pada keadaan ن́ Sukun atau p sukun. Penulis menyadari banyak mahasiswa yang sudah memahami akan hal tersebut, 
sehingga di buku Tajwid Jazariyyah, penulis memberikan penekanan pada hurufhuruf yang harus dibaca jelas ketika bertemu huruf-huruf tertentu.

Seperti pada huruf-huruf yang terdapat di lafal-lafal berikut;

1. Huruf ض ظ bertemu sering dibaca sama atau terlipat, padahal seharusnya diperjelas makhraj masing-masing huruf. Seperti contoh; يوم يعض ,انقض ظهر

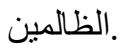

2. Huruf ض bertemu د dan ذ ذ harus dibaca Izhhar, seperti contoh; مله الارض ذهبا ,منضود

3. Huruf ض bertemu b, seperti contoh; فمن اضطر.

4. Huruf ض ض bertemu ت, seperti contoh; افضتم.

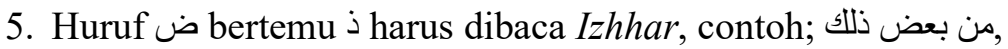

6. Semua huruf Halaq tidak boleh di-Idgham-kan kepada sesama huruf Halaq. Huruf • bertemu ح, seperti contoh; تتبع اهو اهم, ,ابلغه , افرغ علينا ,فسبحه , اتق الله حقا

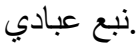

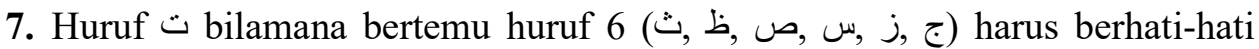
dalam mengucapkan huruf $ت$ agar sifat Hams-nya $ت$ terdengar jelas dan خبت بضجت جلودهم ركنبت ثمود tidak tergelincir menjadi Idgham, seperti contoh كانت ظالمة , لهدمت صوامع ,انزلت سورة ,زدناهم.

8. Berhati-hati dan tidak tergesa-gesa dalam membaca $s$ yang disandingkan dengan $\varepsilon$ agar tidak terlipat $\varepsilon$ menjadi $\varepsilon$ atau $\varepsilon$ menjadi $\&$, seperti contoh; انعsت.

9. Huruf ي Mad yang bertemu dengan ي hidup dam و Mad yang bertemu dengan $و$ hidup menurut kesepakatan para ulama ahli Qira'at wajib dibaca Izhhar, seperti contoh; قالو ا وهم ,فى يوم.

Asalnya $\dot{u}$ ketika sukun, $r$ ketika sukun, dan Tanwin adalah tidak berdengung. Pada bacaan Idzhar ن sukun atau Tanwin yang bertemu dengan huruf Halqi (tenggorokan) wajib menjaga 3 hal yang sering diabaikan oleh orang awam, yakni;

1. Tidak boleh terlalu keras atau terlalu pelan membaca untuk memperjelas. Hal ini dapat menimbulkan huruf atau harakat tambahan, seperti; ان ءعمت

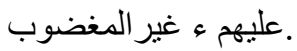

2. Terputus bacaan agak lama sehingga menjadi bacaan Saktah atau malah mengambil nafas, seperti membaca عليهi berhenti sebentar kemudian و والضالين melanjutkan

3. Terlalu kendor sampai keluar bacaan Ghunnah-nya, seperti; عليهم م م وهم م فيها 9 
Ketiga bentuk pembacaan di atas adalah salah dan dianggap menjadi Lahan . Bacaan yang diharapkan setelah menerapkan ilmu Tajwid adalah bacaan yang tengah-tengah, tepat dan enak, tidak mengurangi atau menambahi.

Sistem pembelajaran yang digunakan agar mahasiswa memiliki tanggung jawab dalam hafalannya adalah mengaitkan ketuntasan hafalan dengan presensi kehadiran mahasiswa. Artinya seorang mahasiswa dianggap hadir pada setiap pertemuan perkuliahan manakala dapat menyetorkan hafalan yang telah ditentukan. Sebagaimana yang dijelaskan dalam tabel berikut ini.

Tabel 1. Deskripsi kompetensi Hafalan Juz 'Amma

\begin{tabular}{|c|l|}
\hline Pertemuan & Materi Surat Juz 'Amma \\
\hline $\mathbf{1 .}$ & $\begin{array}{l}\text { An-Nasr, al-Kafirun, al-Kautsar, al- } \\
\text { Ma'un }\end{array}$ \\
\hline $\mathbf{2 .}$ & An-Nas, al-Falaq, at-Thariq \\
\hline $\mathbf{3 .}$ & Al-Ikhlas, Al-Lahab, al-A'la \\
\hline $\mathbf{4 .}$ & Al-Quraisy, Al-Fil, al-Ghasyiyah \\
\hline $\mathbf{5 .}$ & Al-Humazah, al-'Asr, al-Fajr \\
\hline $\mathbf{6 .}$ & At-Takatsur, al-Qari'ah, Al-Balad \\
\hline $\mathbf{7 .}$ & Al-'Adiyat, al-Zilzalah, Asy-Syams \\
\hline $\mathbf{8 .}$ & Al-Bayyinah, Al-Qadr. al-Lail, \\
\hline $\mathbf{9 .}$ & Al-'Alaq, at-Tin, an-Naziat \\
\hline $\mathbf{1 0 .}$ & ad-Dhuha, Al-Insyirah, an-Naba' \\
\hline $\mathbf{1 1}$ & 'Abasa, at-Takwir, Al-Infitar \\
\hline $\mathbf{1 2}$. & al-Mutaffifin, al-Insyiqaq, al-Buruj \\
\hline
\end{tabular}

Juz 'Amma (Juz ke-30 dari Al-Qur'an) dibagi atas 12 pertemuan untuk menjadi kompetensi yang harus dikuasai oleh mahasiswa PGMI UNISDA. Susunan surat sengaja dibuat tidak urut sesuai urutan yang tertulis dalam mushaf Al-Qur'an, dengan alasan untuk mempermudah hafalan. Surat-surat yang panjang dimasukkan di setiap pertemuan agar tidak terkumpul surat-surat panjang pada pertemuan akhir. Dosen pengampu menyadari bahwa tidak semua mahasiswa PGMI berasal dari Madrasah Aliyah atau pondok pesantren yang barang tentu sudah familiar dengan hafalan surat Al-Qur'an. Hal ini menjadi kendala perkuliahan. Bahkan terkadang terdapat mahasiswa yang bacaan Al-Qur'annya masih perlu banyak belajar. Dosen pengampu mengatasi permasalahan ini dengan menyuruh mahasiswa yang bersangkutan untuk belajar kepada yang sudah mahir. Mengingat matakuliah Pembelajaran Tahfidz dan Tajwid di program studi PGMI UNISDA hanya mendapat alokasi waktu 2 SKS. Sehingga tidak mungkin dosen mengatasi seluruh persoalan terkait bacaan mahasiswa.

Pembelajaran Tahfidz dan Tajwid merupakan tingkatan di atas pembelajaran baca tulis Al-Qur'an seperti di TPQ. Idealnya seorang mahasiswa 
mendapat matakuliah ini setelah tuntas matakuliah pembelajaran Qur'an-Hadis MI. Sebagaimana yang tertulis dalam silabus mata kuliah Tahfidz dan Tajwid, bahwa tujuan perkuliahan adalah mahasiswa menguasai kompetensi psikomotorik dalam membunyikan bacaan surat-surat Juz 'Amma bi al-ghaib (hafalan) dengan tartil dan nada yang merdu sebagai ketrampilan yang menunjang profesi pengajar anak usia dini dalam dimensi pendidikan Islam. Mahasiswa menguasai kompetensi kognitif terkait ilmu Tajwid terlebih pada Makharij al-Huruf, Sifat al-Huruf, Tarqiq dan Tafkhim.

Dalam praktekn ${ }^{15}$ ya, seluruh mahasiswa bersama-sama melantunkan doa pemudah hafalan yang berbentuk syair di awal pertemuan sebagaimana berikut.

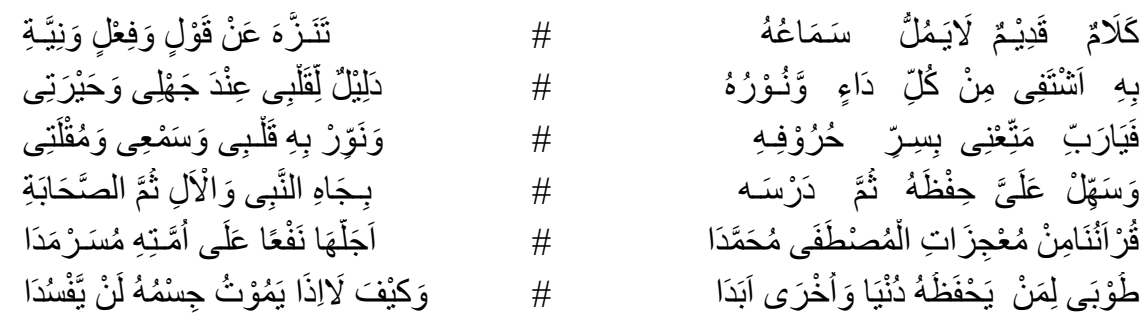

Selanjutnya mahasiswa melantunkan bacaan Al-Fatihah dan surat-surat yang nantinya disetorkan dengan lagu yang telah disepakati. Lagu bacaan AlQur'an diseragamkan sesuai kemampuan mereka. Semisal banyak dari mahasiswa menguasai lagu metode Qiroati, maka disepakati mahasiswa lainnya bisa menggunakannya. Lagu bacaan penting mereka kuasai karena kelak mereka akan mengajarkan anak-anak usia MI yang notabene lebih antusias untuk melantunkan Al-Qur'an ketika dilagukan.

Selanjutnya dosen menawarkan poin tambahan bagi 3 mahasiswa yang berani menyetorkan di awal. Dari mahasiswa yang telah menyetorkan di awal dan dinilai hafalan dan bacaannya baik diminta untuk menjadi asisten dosen dengan menyimak bacaan mahasiswa lain. Di satu sisi, metode ini dianggap lebih efisien agar seluruh mahasiswa mendapatkan kesempatan untuk menyetorkan hafalannya. Di sisi lain, mahasiswa penyemak bertambah kuat hafalannya.

Dosen juga terbantu untuk memaksimalkan waktu perkuliahan untuk dapat menilai seluruh mahasiswa. Ketika dijumpai mahasiswa yang datang terlambat, dosen memberikan punishment yang mendidik berupa mendahulukan giliran mahasiswa yang terlambat. Jika mahasiswa tersebut belum hafal, maka dosen menyuruhnya untuk menghafal sambil jongkok. Terbukti dengan adanya punishment ini, mahasiswa takut untuk mengulangi kesalahan yang sama.

15 Wawancara dengan Akhmad Yusron, M.Pd.I, selaku dosen pengampu matakuliah Pembelajaran Tahfidz dan Tajwid, pada tanggal 13 April 2018. 
Bagi mahasiswa yang belum hafal surat-surat pada suatu pertemuan, bisa meng-qadla' (mengganti) di pertemuan selanjutnya. Mahasiswa dapat mengikuti ujian baik UTS ataupun UAS, jika sudah tuntas hafalan surat-surat Al-Qur'an pada pertemuan-pertemuan sebelumnya. Ujian Tengah Semester (UTS) dibuat dalam bentuk penugasan membuat video selfie yang menayangkan bacaan suratsurat yang telah dihafalkan pada pertemuan sebelumnya dan diurutkan sesuai urutan di mushaf. Pada akhir pertemuan atau pada saat pelaksanaan Ujian Akhir Semester, mahasiswa harus tuntas hafalan Juz 'Amma. Tuntas hafalan juz 'Amma dibuktikan dengan presensi yang penuh. UAS dilaksanakan dalam bentuk Munaqasah (sidang ujian). ${ }^{16}$

Pada waktu yang telah ditentukan, mahasiswa berbaris sesuai dengan undian yang didapat. Berdasar urutan, mahasiswa bergiliran untuk dievaluasi tingkat kemampuan hafalannya dengan meneruskan bacaan yang disebutkan oleh dosen penguji. Strategi pembelajaran ini terbukti praktis, efektif, dan efektif untuk mendorong mahasiswa untuk dapat memiliki kompetensi hafalan Juz 'Amma.

Apabila rancangan pembelajaran terpenuhi dan mahasiswa mengindahkannya dengan baik, maka tujuan pembelajaran mata kuliah Tahfidz dan Tajwid dapat terealisasi. Bukti kesuksesan dari strategi pembelajaran ini adalah terdapat mahasiswa yang berhasil meraih juara pertama di Musabaqah Tartil Qur'an di IMPI (ikatan mahasiswa PGMI se-Indonesia). ${ }^{17}$

\section{Kesimpulan}

PGMI UNISDA menghadirkan suatu matakuliah Pembelajaran Tahfidz dan Tajwid didasarkan pada kebutuhan pangsa pasar di daerah Lamongan. Ilmu Tajwid merupakan salah satu bagian dari Ulum al-Qur'an. Alasan yang menjadikan seorang Muslim berkewajiban belajar ilmu Tajwid. Belajar ilmu Tajwid merupakan kewajiban dan banyak keutamaan yang ditawarkan. Bacaan Tartil dapat diwujudkan melalui pembelajaran ilmu Tajwid. Strategi pembelajaran matakuliah Tahfidz dan Tajwid di PGMI UNISDA berpedoman pada buku Tajwid Jazariyyah yang telah disusun oleh dosen pengampu. Buku terjemah dari kitab Matan Jazariyyah ini dinilai memiliki materi yang dibutuhkan untuk dapat membaca Al-Qur'an secara fasih. Pembahasan seputar Makharij al-Huruf, Sifat Huruf, Tarqiq dan Tafkhim merupakan kebutuhan pokok untuk dapat membaca Al-Qur'an secara fasih. Sistem pembelajaran yang digunakan dalam pembelajaran Tahfidz dan Tajwid adalah mengaitkan tuntas hafalan dengan presensi kehadiran. Tuntas hafalan Juz 'Amma menjadi syarat seorang mahasiswa dapat mengikuti ujian akhir semester dalam bentuk Munaqasah Juz 'Amma.

16 Wawancara dengan Akhmad Yusron, M.Pd.I, selaku dosen pengampu matakuliah Pembelajaran Tahfidz dan Tajwid, pada tanggal 13 April 2018.

${ }^{17}$ Dokumen piagam penghargaan Juara 1 Lomba Musabaqoh Tartil Qur'an atas nama Siti Zumaroh, pada tanggal 11 Juni 2018. 


\section{DAFTAR PUSTAKA}

Hasyimi, Ahmad. t.th. Mukhtar al-Hadits an-Nabawiyyah, hadits ke-48, Surabaya: Al-Haramain.

Ibn Al-Jazari, Muhammad bin Muhammad, Matan Jazariyyah, t.th. Surabaya: Saad bin Nashir bin Nabhan.

Lajnah Muroqobah Yanbu'a Cabang Mojokerto, Sekilas Ulumul Qur'an dan Fawatissuwar, LMY Cabang Mojokerto, 2012.

Yusron, Akhmad, 2018. Tajwid Jazariyyah, Lamongan: Unisda Press.

Q.S. Al-Muzzammil ayat 4, Al-Qur'an dan Terjemahannya, Depag RI, Jakarta, 2002, hlm. 846

Wawancara dengan Akhmad Yusron, M.Pd.I, selaku dosen pengampu matakuliah Pembelajaran Tahfidz dan Tajwid, pada tanggal 13 April 2018.

Dokumen piagam penghargaan Juara 1 Lomba Musabaqoh Tartil Qur'an atas nama Siti Zumaroh, pada tanggal 11 Juni 2018.

Wawancara dengan Ibu Hj. Isti'anah Nikmah, selaku Kepala MI Darul Ulum 2 Kudus, pada tanggal 12 Februari 2016.

Dokumentasi pada tanggal di Gedung Asrama Haji Tuban. 